УДК 621.771 .251

\author{
Найзабеков А. Б. \\ Лежнев С. Н. \\ Панин Е. А. \\ Арбуз А. С.
}

\title{
ВЛИЯНИЕ РАДИАЛЬНО-СДВИГОВОЙ ПРОКАТКИ НА МИКРОСТРУКТУРУ И МЕХАНИЧЕСКИЕ СВОЙСТВА ТЕХНИЧЕСКОГО ТИТАНА
}

С неуклонным ростом качества и продолжительности жизни возрастает роль имплантации, призванной заменить поврежденные либо пораженные части организма человека с целью обеспечения восстановления утраченных функций. В настоящее время имплантация представляет широкое поле деятельности от зубных протезов до искусственных суставов, элементов позвоночника, искусственного сердца и разрабатываемых вживляемых электронных чипов для восстановления функций центральной нервной системы [1].

Все виды имплантатов объединяет одно общее требование - биосовместимость, то есть способность материала встраиваться в организм пациента, не вызывать побочных клинических проявлений и индуцировать клеточный или тканевой ответ, необходимый для достижения оптимального терапевтического эффекта.

Базовое свойство любого живого организма - отвергать любые чужие тела, которые в него входят. Металлы, вступив в контакт с биологическими жидкостями окисляются, что приводит к процессам ионизации. Неустойчивые ионы металлов, примыкают к чужим протеинам, создавая сложный метал-протеин, который организм ошибочно принимает за угрозу (как вирус или бактерию) и провоцирует защитную реакцию иммунной системы. Начинают умножаться лимфоциты, чтобы преодолеть вторгшийся организм. Происходит воспаление и отторжение. В худшем случае, ионы металлов и металл-протеины, встраиваясь в метаболизм организма, вызывают куда более серьезные изменения.

Биосовместимыми свойствами обладает титан и некоторые другие материалы (цирконий, золото, платина). Золото и платина, издревле используемые для протезирования зубов химически нейтральны, но обладают недопустимо низкими механическими свойствами, что исключает их применение для остеопротезирования, где требуется выдерживать высокие механические нагрузки при небольших размерах. Титан и цирконий, обладая высокими механическими свойствами, образуют на поверхности пассивирующую оксидную пленку [2-3]. Благодаря которой они не корродируют и не отдают свободные ионы металла. Цирконий обладает наилучшей биосовместимостью, однако он более дорог и его механические свойства ниже, чем у титана [4-5]. Большое значение имеет создание высокопрочных длинномерных протезов для замены частей больших костей опорно-двигательного аппарата, например, при раке, когда удаляются большие объемы костей.

Таким образом, разработка технологии повышения механических свойств биосовместимых материалов имеет несомненную актуальность, особенно это касается длинномерных изделий.

Один из путей повышения механических свойств - использование ультрамелкозернистых (УМЗ) и наноструктурных материалов (НС) [6]. Все промышленно используемые металлические материалы, имеют крупнозернистое строение с размерами зерна-кристаллита порядка 20-80 мкм и более. Методами интенсивной пластической деформации, возможно получение ультрамелкозернистого (менее 1 мкм) и наноструктурного (100 нм и менее) состояния тех же материалов, которые при этом, очень сильно меняют свойства. Значительно увеличивается прочность при сохранении либо небольшом уменьшении пластичности. Такое сочетание 
свойств, критически важно для ответственных изделий, где важен вес и размер детали. Например, для медицинских имплантантов, которые при сохранении равной прочности, можно сделать тоньше, и, в случае превышения нагрузки - он не разрушится, повреждая окружающие ткани, а лишь погнется и может быть впоследствие заменен. Подробно эти материалы были изучены в работах Валиева P. 3. [6], Horita Z., [7] Langdon T. G. [8] и др. [9-13].

Наиболее популярные методы, реализующие эти условия: равноканальное угловое прессование (6-8 циклов и более) [13], кручение под высоким давлением [8]. На долю этих способов приходится более 90 \% публикаций об УМЗ материалах и 90 \% публикаций по исследованию биосовместимости УМЗ материалов. Эти методы дают проработанную структуру и очень просты в реализации. Однако, их главный недостаток, препятствующий широкому промышленному внедрению - ограничения в размерах образцов и крайне низкая технологичность производства. Устранить эти недостатки можно, используя такой способ, как радиально-сдвиговая прокатка, которая также позволяет получать УМЗ состояние, но уже в длинномерных круглых прутках с некоторыми особенностями распределения структуры [9, 14-15]. Разработка данного способа позволит сделать шаг в сторону широкого применения имплантатов из УМЗ материалов.

В очаге деформации радиально-сдвиговой прокатки реализуется схема напряженнодеформированного состояния, близкая к всестороннему сжатию с большими сдвиговыми деформациями, являющаяся благоприятной для формировании УМЗ структуры.

Основной особенностью радиально-сдвиговой прокатки является немонотонность и турбулентность деформации, а также отличия в пластическом течении и проработке структуры разных зон заготовки вследствие траекторно-скоростных особенностей процесса [15-16]. В силу этих особенностей течения металла, наиболее интенсивные сдвиговые деформации локализуются в зоне пересечения линий скольжения металла - кольцевой зоне поперечного сечения характерной для трехвалковой схемы, что подтверждается моделью. Во внешнем слое каждый малый траекторно-ориентированный элемент подвергается деформации сжатия по радиусу заготовки, деформации сжатия по направлению истечения (вдоль винтовой траектории) и, соответственно, деформации растяжения поперек винтовой траектории. При этом важно, что имеется постоянный градиент скоростей и направлений течения по радиусу, который еще добавляет дополнительные сдвиговые элементы в общую сложную картину напряженнодеформированного состояния. Элементы структурного строения металла, подвергнутые расширяющемуся течению с двухсторонней осадкой (вдоль траектории и вдоль радиуса) приобретают форму изотропных обособленных частиц высокой дисперсности [16].

Скорость частиц в осевом волокне и его длина так же, как и при продольной прокатке увеличивается пропорционально коэффициенту вытяжки. Сечение центральных трубок тока уменьшается. Проработка структуры металла действует по типу продольной прокатки в калибрах с многосторонним обжатием или прессования. Элементы структурного строения вытягиваются и утоняются с образованием характерной структурной полосчастости [4]. Эти особенности подробно описаны и иллюстрированы в работах С. П. Галкина [14-17].

На основе перечисленных выше работ в НИТУ «МИСиС» были созданы конструкции станов радиально-сдвиговой прокатки, реализующие интенсивную пластическую деформацию прокатки сплошного круглого прутка. В их числе, стан СВП-08, поставленный в Рудненский индустриальный институт. Внешний вид стана показан на рис. 1.

Стан СВП-08 предназначен для горячего деформирования прутков сплошного круглого профиля из практически любых металлических материалов, включая малопластичные, непрерывнолитые и порошковые. Прокатка прутков диаметром 10-25 мм осуществляется в трехвалковой клети специальной жесткой конструкции из исходных заготовок диаметром 15-30 мм путем их обжатия по диаметру за один или несколько проходов с применением валков специальной калибровки, и при необходимости, с промежуточными подогревами. Диаметр валков 56 мм; коэффициент вытяжки достигает: 1,1-5,0; производительность стана: 0,1-0,3 т/ч; мощность главных приводов $3 \times 7,5$ кВт. 


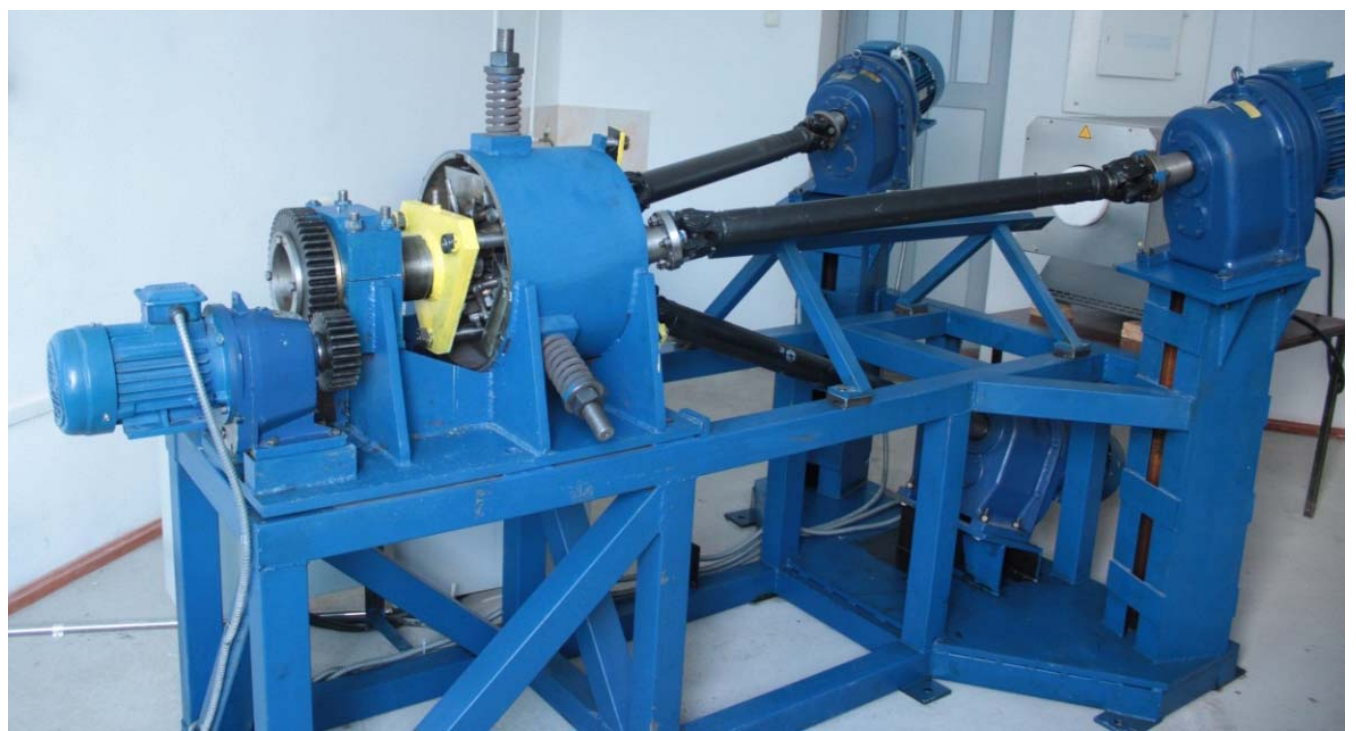

Рис. 1. Стан радиально-сдвиговой прокатки СВП-08

Этот стан был выбран для проведения экспериментов по изучению влияния поперечно-винтовой прокатки на микроструктуру стали, поскольку стан отличается широким сортаментом, высокой жесткостью клети и удобством эксплуатации.

Для проведения опыта был использован пруток с начальным диаметром 30 мм марки BT1. Титан данной марки обладает механическими свойствами, соизмеримыми с механическими свойствами нержавеющих сталей, а легированием титана и термической обработкой сплавов на его основе можно достигнуть уровня прочности высокопрочных сталей. При этом особенно высока удельная прочность титановых сплавов, учитывая плотность железа и тита-

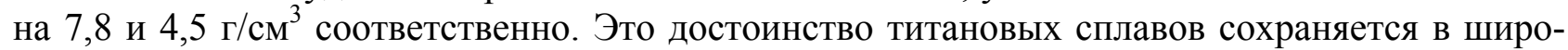
ком интервале температур от -253 до $500{ }^{\circ} \mathrm{C}$.

Химический состав титана марки ВТ-1 (0,08 \% C; до 0,25\% Fe; до 0,07 \% C; до $0.1 \%$ $\mathrm{Si}$; до 0,04 \% N; до 0,2 \% O, 99,24-99,7 \% Ti). Механические свойства титанового прутка имеют следующие значения: предел прочности при растяжении $\sigma_{b}=704 \mathrm{MПа,} \mathrm{относительное}$ удлинение $\delta=26 \%$.

Температура прокатки была выбрана постоянной и равной $500^{\circ}$ С. За 5 проходов, с обжатием по 3 мм в каждом, заготовка была прокатана с 30 мм до 15 мм с интенсивным охлаждением прутка водой после последнего прохода. Подобный температурный режим для получения УМЗ структуры титана был использован в работах [11-12].

После прокатки из прутка были вырезаны цилиндры длиной 30 мм. На высокоточной отрезной машине AccuTom-5 (Struers, Швейцария) вдоль прутка были нарезаны образцы для механических испытаний, в виде полосок $30 \times 3 \times 0,3$ мм. Центральное (наибольшее) сечение было использовано для приготовления образцов для исследования тонкой структуры на просвечивающем электронном микроскопе. Оставшаяся массивная половина была использована для измерения микротвердости по сечению прутка.

Микроструктура была исследована на просвечивающем электронном микроскопе JEM-2100 (JEOL, Япония) при ускоряющем напряжении 200 кВ. Образцы для исследования готовились методом электролитического утонения на установке TenuPol-5 (Struers, Швейцария). Исследование проводилось на тонких фольгах, вырезанных из периферийной и из осевой зон прутка вдоль направления прокатки. Наиболее характерные виды микроструктуры обоих частей прутка показаны на рис. 2 и 3.

Микроструктура периферийной и осевой зон после радиально-сдвиговой прокатки различаются. Периферия прутка представляет собой равноосную ультрамелкозернистую структуру зернами размером 300-600 нм. Зерна имеют высокие углы разориентировки, что установлено по дифракционной картине. Такая структура сопоставима с результатами известных исследований по воздействию ИПД на титан [10-12]. 


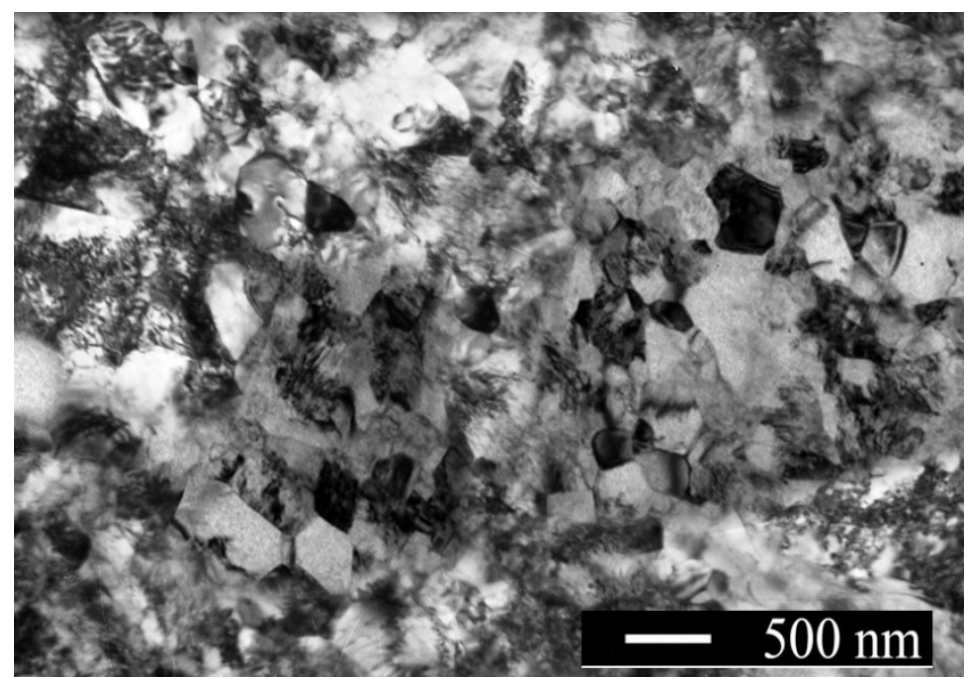

Рис. 2. Структура периферийной части прутка после радиально-сдвиговой прокатки

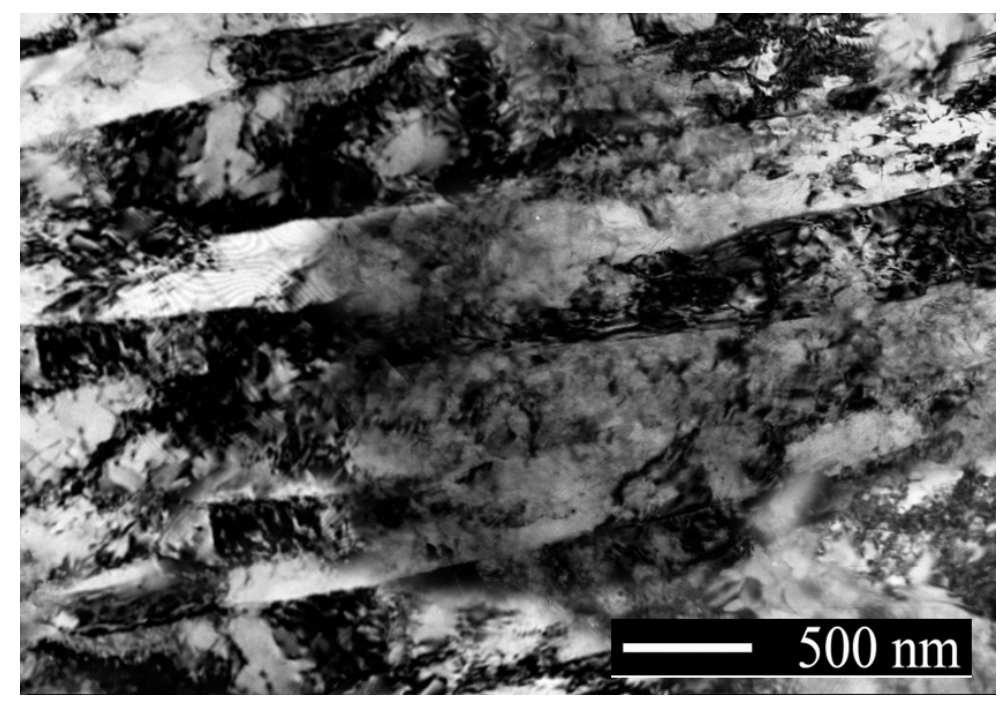

Рис. 3. Структура осевой части прутка после радиально-сдвиговой прокатки

Микроструктура осевой зоны после радиально-сдвиговой прокатки имеет собой волокнистую текстуру подобную прокатной. Длинные и узкие зерна осевой зоны вытянуты в направлении прокатки. Дифракционная картина также подтверждает небольшие углы разориентировки зерен. Подобная разница структуры может быть объяснена разной схемой истечения металла. В периферийной части прутка, где преобладала сдвиговая деформация с высокой турбулентностью течения металла, произошло формирование равноосной УМЗ структуры. В осевой зоне, где течение металла имело ламинарный характер вдоль оси прокатки, сформировалась вытянутая, ориентированная структура. Полученные результаты могут быть сравнены с результатами исследований $[9,15,17]$.

Технический титан марки ВТ-1 в исходном состоянии имеет крупнозернистую структуру со средним размером зерен 70-80 мкм. За 5 проходов радиально-сдвиговой прокатки с суммарной вытяжкой 4, на периферии прутка удалось получить равноосную УМ3 структуру, подобную получаемой другими способами ИПД при схожих степенях деформации и температурах.

Для определения механических свойств были использованы плоские образцы, вырезанные на расстоянии 0,5 диаметра прутка. Учитывая структурную неоднородность периферийной и осевой зоны, такое расположение тестовых образцов будет более объективным. Испытания на растяжение были проведены на испытательной машине Instron-1195 (ITW Inc., CША). Для определения среднего значения в каждой точке, проводилось испытание 5 образов. 
Предел прочности после радиально-сдвиговой прокатки возрос с 704 МПа до 1215 МПа, что составляет $58 \%$. Относительное удлинение изменилось с исходного $26 \%$ до $11 \%$ после пятого прохода. Снижение пластичности в данном случае находится в нормальных пределах для материалов, прошедших подобную обработку, и сопоставимо с результатами известных исследований [10-12].

Изменение механических свойств по проходам предела прочности по проходам показано на рис. 4 и 5.

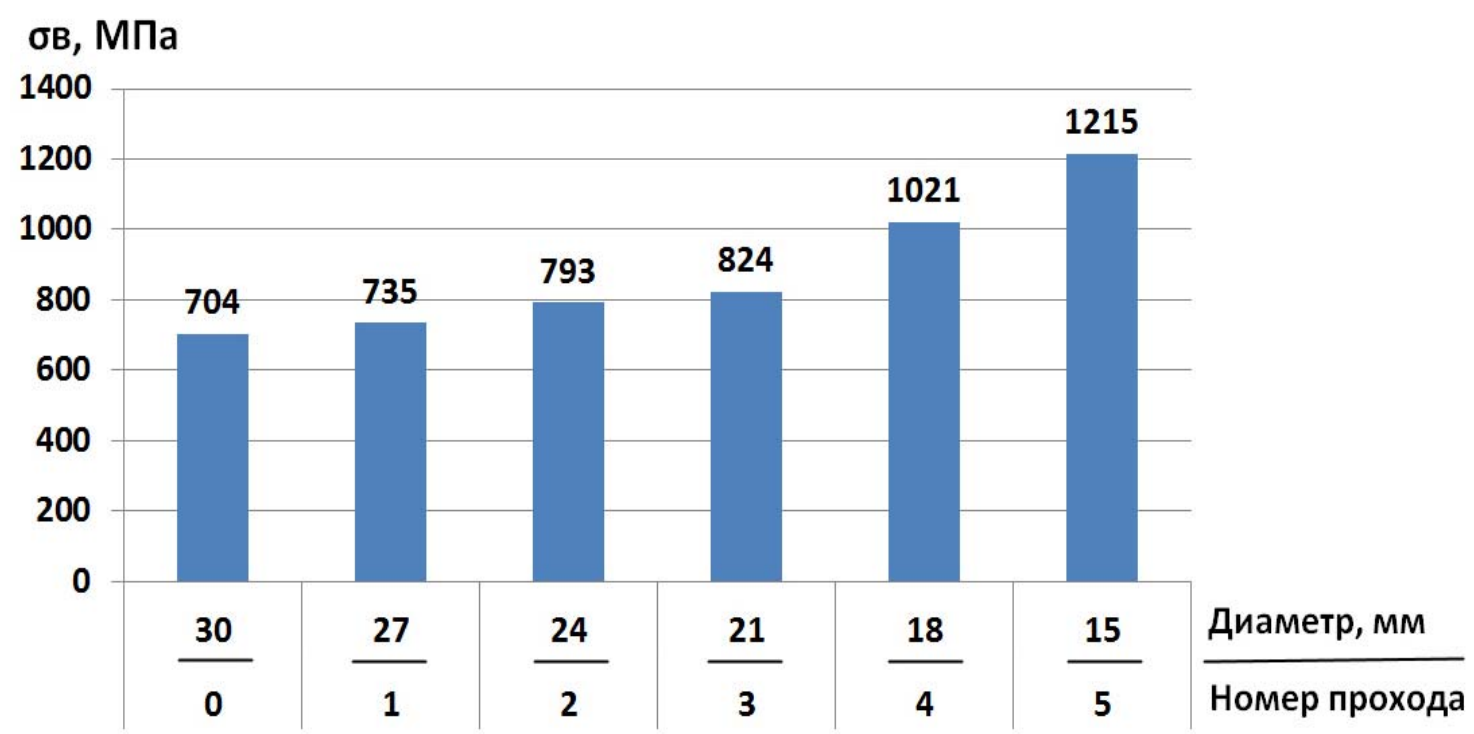

Рис. 4. Изменение предела прочности титана марки ВТ-1 после радиально-сдвиговой прокатки по проходам

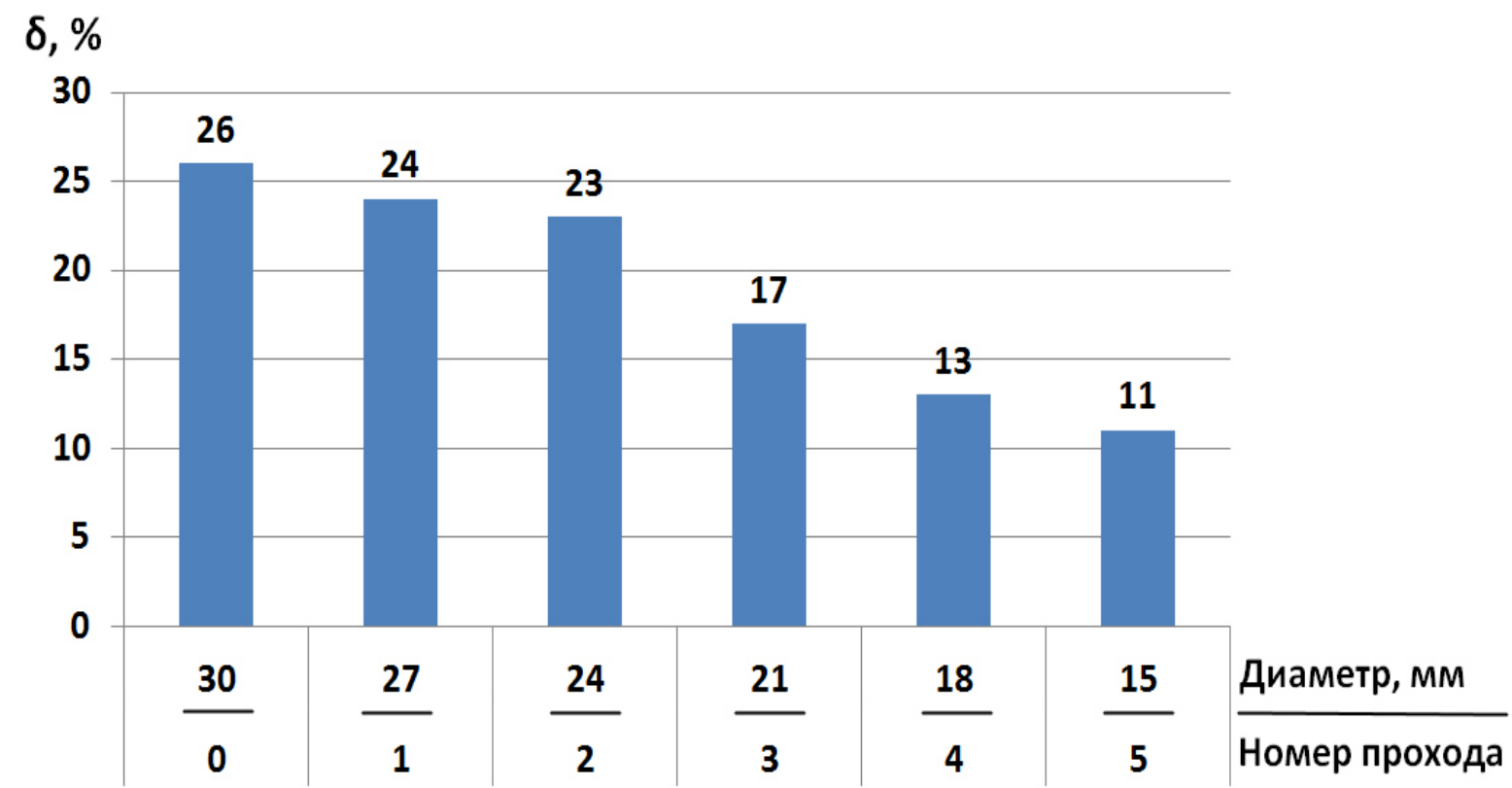

Рис. 5. Изменение относительного удлинения титана марки ВТ-1 после радиальносдвиговой прокатки по проходам

Учитывая имеющуюся структурную неоднородность, возможный уровень неоднородности механических свойств было решено оценить путем измерения профиля микротвердости по сечению прутка после радиально-сдвиговой прокатки. Профиль микротвердости был построен по результатам измерений в 15 последовательных точках расположенных через 1 мм друг от друга. В каждой токе было проведено по 3 измерения в направлении 
перпендикулярном линии профиля, результаты усреднены. Измерение микротвердости проводилось на микротвердомере HVS-1000B (Winex Instrument, Великобритания) по Виккерсу с усилием 9,87 Н при выдержке 15 секунд. График изменения микротвердости по сечению показан на рис. 6.

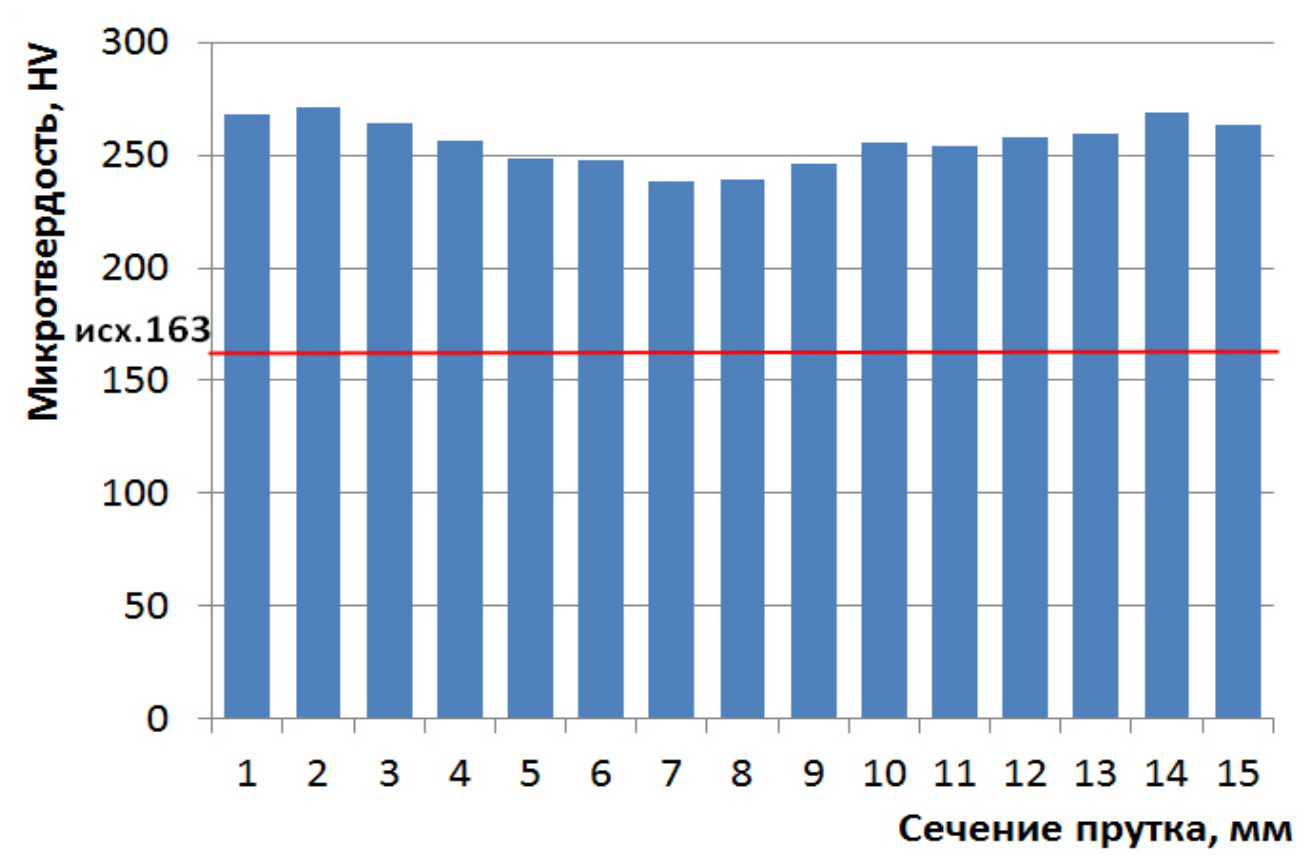

Рис. 6. Изменение микротвердости титана марки ВТ-1 по сечению прутка после радиально-сдвиговой прокатки

После радиально-сдвиговой прокатки, уровень микротвердости поднялся с исходного значения $163 \mathrm{HV}$ до 238-271 HV, что достигает 60\%. При этом, вследствие структурной неоднородности по сечению прутка наблюдается плавное падение уровня микротвердости центральной зоны прутка на 12,4 \% (32,9 HV) относительно периферии. Данные цифры позволяют предположить сопоставимую разницу в уровне остальных механических свойствах по сечению прутка и заключить, что эта разница относительно невелика, а измеренные ранее значения предела прочности и относительного удлинения могут изменяться в указанных выше относительных пределах.

\section{ВЫВОДЫ}

Способом радиально-сдвиговой прокатки за 5 проходом при температуре $500{ }^{\circ} \mathrm{C}$, с суммарной вытяжкой 4, в одном прутке была получена микроструктура двух типов. На периферии прутка сформировалась равноосная ультрамелкозернистая структура с размером зерна в 300-600 нм, в то время как в осевой зоне прутка была ориентированная, полосчатая текстура подобная прокатной.

Полученная микроструктура хорошо согласуется с данными исследований $[9,15,17]$. При этом, получение подобной структуры одним из наиболее распространенных способов ИПД - равноканальным угловым прессованием, требует не менее 6-8 циклов прессования [6-7, 11-12] и возможно только для заготовок небольшой длины, в то время как на стане винтовой прокатки она получается за 4-5 проходов для заготовок неограниченной длины. Проблемой является неоднородность структуры в осевой и периферийной зонах прутка. Однако относительно небольшое различие уровня микротвердости этих зон позволяет надеяться на возможность применения таких прутков для изготовления специальных особопрочных деталей сопоставимой формы. Также имеет смысл рассматривать цельный пруток с двумя разными типа микроструктуры в центре и на периферии как композитный материал либо использовать только периферийную зону. 
Совершенствование способа радиально-сдвиговой прокатки позволит получать материалы с наименьшими затратами времени и энергии, что приведет к удешевлению производства УМЗ материалов и вероятно к коммерческой рентабельности.

\section{REFERENCES}

1. Biomaterials in orthopedics / M. Navarro, A. Michiardi, O. Castaño and J.A Planell // J. R. Soc. Interface. - 2008. - № 5. - Pp. 1137-1158.

2. Olmedo D. An experimental study of the dissemination of Titanium and Zirconium in body. Journal of materials science / D. Olmedo, M. B. Guglielmotti, R. L. Carbini // Materials in medicine. - 2002. - № 13. - Pp. $793-796$.

3. Biocompatibility and osteogenesis of refractory metal implants, titanium, hafnium, niobium, tantalum and rhenium / H. Matsuno, A. Yokoyama, F. Watari, M. Uo, T. Kawasaki // Biomaterials. - 2001. - № 22. - Pp. $1253-1262$.

4. Correlation $\mathrm{Y}$. H. between microstructure and corrosion behavior of $\mathrm{Zr}-\mathrm{Nb}$ binary alloy. Journal of $\mathrm{Nu}$ clear // Materials. - 2002. - № 302. - P. 9-19.

5. Current Status of Zirconia Used in Total Hip Implants / I. C. Clarke, M. Manaka, D. D. Green, MS. P. WilliamS, G. Pezzotti, Y.-H. Kim, M. Ries, N. Sugano, L. Sedel, C. Delauney, B. Ben Nissan, T. Donaldson, G. A. Gustafson // The Journal OF Bone and Joint Surgery, Incorporated.

6. Valiev R. Z. Bulk nanostructured materials from severe plastic deformation / R. Z. Valiev, R. K. Islamgaliev, I. V. Alexandrov // Progress in Materials Science. - 2000. - Vol. 45. - № 2. - P. 103-189.

7. Terence $G$. Langdon. The characteristics of grain refinement in materials processed by severe plastic deformation / T. G. Langdon // Rev. Adv. Mater. Sci. - 2006. - Vol. 13. - P. 6-14.

8. Xu C. The evolution of homogeneity in processing by high-pressure torsion / C. Xu, Z. Horita, T.G. Langdon // Acta Materialia. - 2007. - Vol. 55. - № 1. - P. 203-212.

9. Effect of cross rolling on the microstructure of steel / Naizabekov A., Lezhnev S., Tsay K., Arbuz A. // Nanocon 2015, 7th International Conference on Nanomaterials - Research \& Application. 14 ${ }^{\text {th }}-16$ th Oct 2015 , Brno, Czech Republic, EU.

10. A. Balyanov, J. Kutnyakova, N. A. Amirkhanova, V. V. Stolyarov, R. Z. Valiev, X. Z. Liao, Y. H. Zhao, Y. B. Jiang, H. F. Xu, T. C. Lowe, Y. T. Zhu. Corrosion resistance of ultra fine-grained Ti Scripta Materialia. - 2004.№ 51. - P. 225-229.

11. Meredith C.S. Texture evolution and anisotropy in the thermo-mechanical response of UFG Ti processed via equal channel angular pressing / C. S. Meredith, A. S. Khan // International Journal of Plasticity. - 2012. - № 30-31. - Pp. $202-217$.

12. Long-length Ultrafine-grained Titanium Rods produced by ECAP-Conform / G. I. Raab , R. Z. Valiev , D. V. Gunderov, T. C. Lowe, A. Misra, Y. T. Zhu. // Materials Science Forum Vols. 584-586 (2008) pp 80-85

13. Valiev Z. R. Principles of equal-channel angular pressing as a processing tool for grain refinement / R. Z. Valiev, T. G. Langdon // Progress in Materials Science. - 2006. - № 51. - P. 881-981.

14. Lopatin N. V. Mathematical modeling of radial-shear rolling of the VT6 titanium alloy under conditions of formation of a globular structure / N. V. Lopatin, G. A. Salishchev, S. P. Galkin // Russian Journal of Non-Ferrous Metals. - 2011. - № 52 (5). - P. 442-447.

15. Galkin S. P. Radial shear rolling as an optimal technology for lean production / S. P. Galkin // Steel in Translation. - 2014. - № 44 (1). - P. 61-64.

16. Patent RF № 2293619, B21B19/00. Sposob vintovoj prokatki / Galkin S. P. - opubl. 20.02.2007.

17. Grain refinement, texture, and mechanical properties of a magnesium alloy after radial-shear rolling / Dobatkin S., Galkin S., Estrin Y., Serebryany V., Diez M., Martynenko N., Lukyanova E., Perezhogin V. // Journal of Alloys and Compounds. - Feb. 2019. - Vol. 774, № 5. - Pp. 969-979.

Найзабеков А. Б. - д-р техн. наук, проф. РИИ;

Лежнев С. Н. - канд. техн. наук, проф. РИИ;

Панин Е. А. $\quad-\mathrm{PhD}$, ст. преп. КГИУ;

Арбуз А. С. $\quad-\mathrm{PhD}$, ст. преп. НУ.

РИИ - Рудненский индустриальный институт, г. Рудный, Казахстан.

КГИУ - Карагандинский государственный индустриальный университет, г. Темиртау, Казахстан.

НУ - Назарбаев Университет, г. Астана, Казахстан.

E-mail: Sergey_legnev@mail.ru 